\title{
Condena por delito de maltrato animal: Sentencia no 363/2013 del Juzgado de Instrucción no 4 de Barakaldo (Bizkaia)
}

\author{
María González Lacabex ${ }^{1}$ \\ Letrada de la acusación particular.
}

Los hechos de los que deriva la presente sentencia son los siguientes:

El día 9 de enero de 2013, la condenada acudió a una clínica veterinaria para solicitar la baja del microchip de su perro. Para ello manifestó que el animal había fallecido y que ya había sido enterrado. Una declaración que resultó ser falsa, con el objetivo de tratar de encubrir los verdaderos hechos: que introdujo al perro en una bolsa con piedras en su interior, atada fuertemente con una cuerda, para posteriormente tirarla en una suerte de vertedero al fondo de un barranco, en un monte de la zona.

Como consecuencia de estos hechos, Tei fue encontrado por un testigo en grave estado de salud: actitud atemorizada, caquexia avanzada, pérdida o deterioro de masa muscular e incoordinación de la misma, que le impedía mantenerse en pie; cuadro de inflamación gástrica e intestinal muy marcado, con presencia de restos radiopacos en el intestino y sangre en las heces, lesiones dérmicas en las extremidades; pérdida del ojo izquierdo y derrame sanguíneo en la córnea del derecho.

\footnotetext{
${ }^{1}$ María González Lacabex: Abogada. Máster en Derecho del Medio Ambiente. Especialista Universitaria en Desarrollo Sostenible y Agenda 21 Local. Postgrado Animales, Derecho y Sociedad (UAB, 2011). Promotora de ANIMALEX, despacho dedicado exclusivamente a Derecho Animal.
} 
La sentencia condena a la mujer, como autora de un delito de maltrato animal (artículo 337 Código Penal $^{2}$ ), a la pena de 8 MESES DE PRISIÓN e inhabilitación especial para el derecho de sufragio pasivo durante el tiempo de la condena, así como inhabilitación especial por tiempo de 2 años para el ejercicio de profesión, oficio o comercio que tenga relación con los animales. La condena incluye también el pago de 812,60 euros a la Asociación Protectora de Animales SOS Bilbao, en concepto de indemnización, así como la totalidad de las costas causadas.

Esta sentencia pone fin a un procedimiento iniciado por la denuncia penal que en su momento interpuso la citada Asociación y que fue objeto de varias transformaciones procesales hasta llegar a la resolución final. Así, aunque en un principio la denuncia se tramitó por el procedimiento de faltas, posteriormente el mismo fue transformado en Diligencias Previas (al reconocer este Juzgado de Instrucción que los hechos eran constitutivos de un presunto delito de maltrato animal, y no de falta), para convertirse finalmente en Diligencias Urgentes (procedimiento de juicio rápido).

Consideraciones procesales al margen, existen tres cuestiones que en mi opinión merece la pena destacar en relación con esta sentencia, siquiera a modo de breves apuntes para la reflexión:

\section{Primera.- Sobre la prueba y el chip identificativo.}

Sin perjuicio del innegable valor probatorio de los informes veterinarios y las testificales que acompañaron a la denuncia interpuesta, en este caso, si ha habido una prueba con un peso especial, ésa ha sido sin duda alguna el chip identificativo que portaba la víctima.

\footnotetext{
${ }^{2}$ Código Penal: http://www.derechoanimal.info/bbdd/Documentos/839.doc
} 
La identificación es una obligación de carácter administrativo establecida por la normativa de protección animal vigente en cada Comunidad Autónoma ${ }^{3}$ y cuyo deber de cumplimiento corresponde al poseedor o propietario de animales. Una obligación que, al margen de las sanciones económicas derivadas de su incumplimiento, conlleva también interesantes beneficios para los propietarios: rápida localización en caso de extravío; acreditación de propiedad en caso de apropiación indebida, robo... ; configuración de censos y estadísticas reales sobre tenencia de animales, sobre los que poder basar, por ejemplo, una solicitud de habilitación de espacios adecuados para ellos en los municipios; etc.

La identificación obligatoria es también un instrumento esencial para prevenir el abandono y el maltrato animal, así como para exigir responsabilidades en caso de que ya se hayan producido. $Y$ el caso que nos ocupa es un ejemplo claro de lo anterior, en la medida en que el microchip:

- no sólo permitió la inmediata identificación de la propietaria del perro, a quien dirigir las sospechas de autoría en cuanto responsable del mismo,

- sino que resultó absolutamente revelador de, como mínimo, la participación de esta persona en los hechos denunciados, que luego ella misma declararía haber sido en calidad de autora. Así, el chip proporcionó información irrefutable sobre la baja solicitada por la propietaria con motivo de la supuesta muerte del perro, días antes de ser rescatado, así como sobre la clínica veterinaria donde se había tramitado dicha baja, y que aportó el documento de declaración de fallecimiento firmado por la mujer.

No hay duda de que la evidencia de esta prueba favoreció que la entonces imputada, en su defensa, optara por reconocer los hechos en presencia judicial y propició su

\footnotetext{
${ }^{3}$ Puede consultarse la legislación autonómica aplicable a esta materia, bajo la voz "Identificación”, en: http://www.derechoanimal.info/esp/basededatos/index

4 Sobre esta cuestión, véase Sentencia 8398/2010, de la Audiencia Provincial de Madrid: http://www.derechoanimal.info/bbdd/Documentos/829.doc
} 
posterior conformidad con la acusación más grave (propuesta, como veremos, por la acusación particular). Un ejemplo más para volver a insistir en la gran importancia del microchip como instrumento clave dentro de cualquier estrategia de protección animal que se pretenda exitosa.

\section{Segunda.- Sobre la participación de la acusación particular y la pena impuesta.}

El delito de maltrato animal es un delito de carácter público, frente al que el Ministerio Fiscal necesariamente debe ejercitar acción penal, exista o no acusación particular. Sin embargo, el interés práctico de la participación de dicha acusación en procedimientos de este tipo es innegable, ya que ofrece a esta parte la posibilidad de intervenir activamente en todo el proceso, desde la fase de investigación, pasando por el escrito de acusación y el juicio oral, hasta la sentencia final.

En el caso que nos ocupa, el personamiento de APA SOS Bilbao como acusación particular fue especialmente relevante en el trámite de calificación y formulación de la acusación. Y lo fue porque, más allá de defender el encaje de los hechos descritos en el tipo penal del artículo $337 \mathrm{CP}$, la acusación puso el énfasis en tres elementos que consideró claves a la hora de determinar la gravedad de la pena:

1) La intención de la acusada de matar a su perro, para lo cual lo encerró dentro de una bolsa de la que no iba a poder salir, y lo abandonó en el monte. De hecho, si finalmente el animal no falleció fue gracias a que: primero, alguien pasó por allí; segundo, llegó a oír los gemidos; y tercero, lo rescató y lo trasladó inmediatamente a una clínica veterinaria.

2) Dentro del maltrato, la especial crueldad del medio elegido para acabar con la vida del perro, abocado a una muerte con gran sufrimiento físico y padecimiento psicológico: hambre, frío, dolor por lesiones físicas, miedo y angustia.

3) La planificación de los hechos en busca de impunidad, al acudir al veterinario para dar de baja el microchip mintiendo deliberadamente sobre la realidad de 
los hechos, en la errónea confianza de que de este modo se aseguraría la imposibilidad de ser identificada como titular del perro.

Todo ello fundamentó la petición de la acusación particular, a la que después se unió el Ministerio Fiscal: un año de prisión y tres años de inhabilitación especial para el ejercicio de profesión, comercio u oficio relacionado con animales.

La acusada manifestó su conformidad con dicha acusación, de forma que evitó la celebración del juicio oral y obtuvo por ello una reducción de un tercio en la condena recogida en el fallo de la sentencia: ocho meses de prisión y dos años de inhabilitación especial (de acuerdo con lo previsto en el artículo 655 de la Ley de Enjuiciamiento Criminal). Una condena que, casi con toda seguridad, habría resultado sustancialmente menor en caso de no haber existido en el procedimiento acusación particular.

Por último, debemos señalar que fue precisamente la acusación particular quien propuso, asimismo, la correspondiente indemnización en concepto de responsabilidad civil derivada del delito, así como la condena al pago de todas las costas del proceso.

\section{Tercera.- Sobre la responsabilidad civil derivada del delito.}

Considerando el grave estado de salud en que se encontraba el perro y en aras a poder comenzar inmediatamente con el tratamiento necesario para su recuperación física y psicológica, APA SOS Bilbao asumió la custodia y sufragó con sus propios medios los diversos gastos requeridos a tal fin.

El Código Penal establece en su artículo 116.1: "Toda persona criminalmente responsable de un delito o falta lo es también civilmente si del hecho se derivaren daños o perjuicios (...)". En base a dicho precepto y conforme a lo dispuesto en los 
artículos 109 y siguientes del mismo Código, la sentencia condena también a la acusada a indemnizar a esta asociación por la asistencia veterinaria prestada al perro. Respecto a este punto en el curso del procedimiento se planteó la siguiente cuestión: El deficiente estado, no sólo físico, sino sobre todo psicológico en el que se encontraba Tei cuando fue recogido, llevó al veterinario a tomar la decisión de posponer la inevitable intervención quirúrgica de su ojo izquierdo, totalmente perdido. Pues bien, la transformación del procedimiento en Diligencias Urgentes (a raíz del reconocimiento de hechos y posterior conformidad manifestada por la acusada) aceleró de tal manera el proceso que, en el momento de determinar la cuantía de la responsabilidad civil, dicha operación aún no se había realizado. Únicamente existía un presupuesto como prueba de su posible importe. Un presupuesto que, como tal, tenía carácter orientativo, con una cuantía que podía verse modificada o incluso no llegar siquiera a ejecutarse. En definitiva, susceptible de poder ser discutido por la defensa.

En este caso la inminencia de la fecha prevista para la operación posibilitó una breve "suspensión" de las actuaciones hasta que la intervención se hubo realizado y, por tanto, el gasto fue efectivamente ejecutado, de forma que finalmente este concepto pudo ser incluido en el cálculo de la indemnización reclamada por la asociación y a cuyo pago condena la presente sentencia.

¿Qué sucede con aquellos daños que efectivamente se han provocado a un animal maltratado, pero cuyo tratamiento, por diversos motivos, no ha podido ser aplicado en el momento de concretar la cuantía de la responsabilidad civil? Si en este caso el procedimiento hubiera seguido como procedimiento abreviado, y no como juicio rápido, no se habrían planteado dudas respecto a la inclusión o no de los gastos por la operación del ojo (porque seguramente ya habría dado tiempo a realizarla). En este sentido ¿puede determinar la duración de un procedimiento la cuantía de la indemnización debida? En realidad, podríamos ir más allá: ¿qué sucede con esos daños 


\section{dA derecho ANIMAL la web center de los animales con derecho}

que son consecuencia directa del maltrato, pero que no "afloran" hasta pasado un tiempo? Con esto me estoy refiriendo, por ejemplo, a los problemas de carácter conductual o de socialización del animal víctima de maltrato, que con el tiempo acaba necesitando un tratamiento de tipo etológico.

Sin duda el análisis de esta cuestión (sobre la que existe una rica jurisprudencia) excede el alcance del presente documento, cuyo objeto se reduce a señalar los que constituyen, en mi opinión, los aspectos más destacados en relación con la Sentencia comentada y el procedimiento seguido hasta ella. Sin embargo, sirva el presente para dejar apuntada una cuestión, la relativa a los llamados "daños futuros", de gran relevancia práctica a la hora de exigir responsabilidades civiles, también en los casos de maltrato animal. Cuestión de gran interés para ser desarrollada, esta vez con carácter monográfico, en una posterior ocasión.

En Getxo, a 8 de julio de 2013. 